\title{
The genetic basis of wing dimorphism in the sand cricket, Gryllus firmus and its relevance to the evolution of wing dimorphisms in insects
}

Derek A. Roff
McGill University, Department of Biology, 1205 Avenue Docteur Penfield, Montreal, Quebec, H3A 1B1.

The sand cricket, Gryllus firmus is dimorphic with respect to wing length, some individuals being micropterous and others macropterous. The trait has a polygenic basis, micropterous parents producing a higher proportion of micropterous offspring than macropterous parents. The heritability of the trait, determined under a fixed photoperiod/temperature regime is $0.62 \pm 0.075$ and $0.68 \pm 0.085$ for males and females respectively. An alternate method of determining heritability based on a modified mid-parent on mean offspring regression is presented. This method is predicted to give an underestimate of heritability but permits an analysis of the separate influences of each parent. This analysis indicates the heritability in males and females to be 0.55 and that there are no maternal effects under the particular rearing conditions. A 5 hour shift in the photoperiod appears not to drastically change the heritability but a change in rearing temperature from $30^{\circ} \mathrm{C}$ to $25^{\circ} \mathrm{C}$ probably reduces it. Field observations suggest that at certain times of the year heritability may be relatively high whereas at others it could be very low. The adaptive significance of wing polymorphism and its evolution is discussed.

\section{INTRODUCTION}

With relatively few exceptions the environment of living organisms is spatially and temporally heterogeneous and hence there must be a continual movement of propagules to colonise empty habitats and counterbalance the inevitable local extinctions (Andrewartha and Birch, 1954; Southwood, 1962). The relative ease with which pterygote insects can be classified as potential dispersers or non dispersers by the presence or absence of functional wings make them ideal models for an examination of this phenomenon.

In the four large orders of pterygote insects, the Orthoptera, Homoptera, Hemiptera and Coleoptera wing dimorphism is common. The most likely general explanation for the evolution and maintenance of such dimorphisms is that although wings permit dispersal over relatively long distances and hence persistence in a heterogeneous environment, the possession of wings and not simply flight carries a fitness "cost" (Roff, 1984; $1986 a$ ). This cost in females appears, in general, to be a reduced fecundity and a delay in the start of oviposition of the winged morph (Dingle, 1980; Harrison 1980; Roff, 1986a). The frequency of the two wing morphs in a population will depend upon the stability of the habitat, the benefits such as increased fecundity of being flightless and the genetic basis of the trait.

The genetic basis of wing dimorphism in insects is not well understood. Studies on a wide variety of insects suggest that although it may in some cases be inherited as a simple mendelian character in others it is polygenic (Harrison, 1980; Roff, $1986 a$ ). In the latter cases the data are comparatively scanty and insufficient to determine the heritability of the trait. Both single locus and polygenic systems can be analyzed within the framework of "threshold characters". It is assumed that loci, or in the case of the single locus system, alleles, interact with their combined effect determining the level of some wing suppressing substance, possibly juvenile hormone (Harrison, 1980; Roff, 1986a). Above a certain level of this substance wing development is suppressed and microptery results. Because the character can only be scored as "present" or "absent" the usual method of genetic analysis, such as parentoffspring regression, cannot be used. The analysis of the inheritance of all or none characters is reasonably well worked out (Dempster and Lerner, 1950; Robertson, 1951; Falconer, 1981; Bull, Vogt and Bulmer, 1982) but requires that large numbers 
of organisms be raised to ascertain within and between family variation in the trait.

The sand cricket, Gryllus firmus is well suited for an analysis of the heritability of wing dimorphism: it is easy to rear, easy to score with respect to wing length (Macropterous, long, and Micropterous, short) and is polymorphic under natural conditions (Veazey et al., 1976). The long term goal of this research is to develop a genetic model that will permit a realistic and testable examination of the interaction between environmental stability and wing polymorphism in $G$. firmus. In this paper I report on experiments designed to estimate the heritability of wing length under several environmental conditions.

\section{MATERIALS AND METHODS}

\section{Species description and rearing method}

Gryllus firmus is a large (adult weight approximately $0.7 \mathrm{gms}$ ) ground dwelling cricket occurring in the southeastern United States (Alexander, 1968). It is closely related to other Gryllus species and recent electrophoretic evidence suggests that it may be distributed further north than hitherto supposed and may hybridise with Gryllus pennsylvanicus (Harrison and Arnold, 1982). In addition, Gryllus bermudensis from the Bermudas is now considered a subspecies of $G$. firmus (Kevan, 1980) indicating that this species has a wide distribution. Its typical habitat is flat sandy areas both inland and bordering ocean beaches (Harrison, 1979). The specimens used in the present study are derived from approximately forty individuals (approximately 20 females) captured at a single locale in northern Florida. Alexander (1968) indicates that $G$. firmus is univoltine with an egg diapause and spring and fall populations. The presence of spring and fall populations produces two population peaks and the appearance of a bivoltine cycle (Veazey et al., 1976). However, diapause is not obligatory for all eggs and thus the two populations are not entirely separate (Walker, 1980). The stock used in the present analysis has been maintained continuously for three years (approximately 15 generations) with no signs of decreased fertility or vitality. This stock is maintained at approximately $100-300$ breeding individuals at a temperature of $25-30^{\circ} \mathrm{C}$. Heat is provided by two 100 watt electric light bulbs operated thermostatically; hence there is no set photo period. For the breeding experiments the crickets were raised in disposable mouse cages $(29 \mathrm{~cm} \mathrm{~L} \times$
$19 \mathrm{~cm} \mathrm{~W} \times 13 \mathrm{~cm} \mathrm{H}$ from Fisher Scientific) with a mesh covered hole (approx. $1 \mathrm{~cm}$ diameter) along the top of each side to provide ventilation. Wooden lids were tried but found to be unsatisfactory due to warping; glass lids proved very satisfactory. Water was provided for the early and middle instars by a cheesecloth wick which passed through a hole in the floor of the cage to a reservoir of water supplied by sitting the rearing cage in another cage containing water: plastic protruberances on the sides of the cages kept the rearing cage above the water level of the reservoir cage. For the final instars water was supplied from glass vials plugged with cotton wool. All cages received either lettuce and Purina ${ }^{(C)}$ cat chow, ad libitum and crushed to provide a range in food particle size, or cat chow and Purina ${ }^{\circledR}$ rabbit chow similarly crushed. Although development time varied on these two diets the proportion macroptery did not differ significantly and the data have been combined for the present analysis.

\section{Experimental Design}

The experimental design is outlined schematically in fig. 1. To avoid, as much as possible, environmental influences via maternal effects an initial parental generation was established at the temperature and photoperiod under which subsequent generations were raised. Heritability of a threshold trait is determined most precisely when the proportion in each category is close to half, the variance in the estimated value being smallest at this value. I therefore, selected a photoperiod and temperature accordingly: the selected regime was

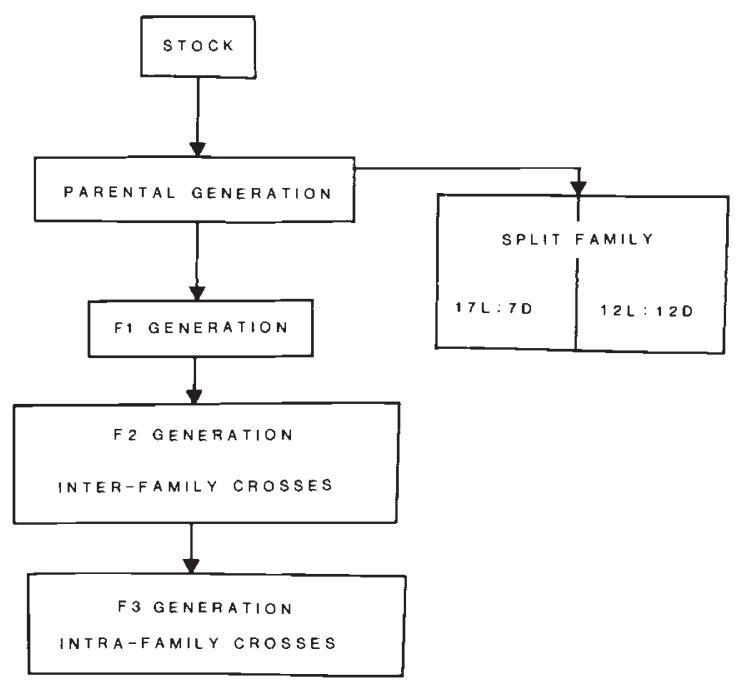

Figure 1 Schematic illustration of experimental design. 
$17 \mathrm{hrs}$ L: $7 \mathrm{hrs} \mathrm{D}$ at $30^{\circ} \mathrm{C}$ which produced an average proportion of macropterous females and males in the combined $F_{1}$ and $F_{2}$ generations of 0.758 and 0.638 respectively.

There is generally no difficulty in differentiating macropterous and micropterous morphs: in the latter the wings are very small and fully hidden by the tegmina. Occasionally an individual had hind wings that protruded beyond the tegmina but were not as long as in the macropterous morph. Of 8574 individuals raised in the $F_{1}$ and $F_{2}$ generations only 1.25 per cent (107) had such intermediate wings. These were discarded from the analysis.

In generations $F_{1}$ and $F_{2}$ all parents for each cross came from different families. In the $\mathrm{F}_{3}$ generation intra-family crosses were made. In general each cross comprised two cages, each started with 60 newly emerged nymphs, the offspring from a single pair mating. Survival averaged 63 per cent giving approximately 76 individuals per family, which gives a reasonably precise estimate of the proportion macropterous. Much of the mortality appears to be due to cannabalism by the males which are very aggressive. There is no indication of selective mortality of the different morphs, the correlation between per cent survival and per cent female macropterous offspring being insignificant $(r=-0 \cdot 14, \quad n=110, \quad P>0 \cdot 10, \quad$ arcsine transformation). Each cage was inspected twice weekly for adults or more frequently as labour permitted. Cages in the parental generation were inspected daily, except on weekends.

Environmental factors may alter the proportion of macropterous individuals produced. To examine the influence of one such factor, photoperiod, on the genetic expression of the trait, 14 families were divided into two groups, one reared at a photoperiod of $17 \mathrm{~L}: 7 \mathrm{D}$ and the other at $12 \mathrm{~L}$ : $12 \mathrm{D}$. Temperature is also known to influence the expression of the trait. No experiments on the effect of temperature using the split family design have yet been undertaken but data are reported on an experiment in which offspring from a mixture of parents were raised at $30^{\circ} \mathrm{C}$ and $25^{\circ} \mathrm{C}$.

\section{Statistical analysis}

Rearing members of the same family in two separate cages permits a preliminary examination of the genetical basis of the trait. If there is a genetic component to macroptery the proportion of macropterous individuals in each cage should be similar. This can be statistically tested with the intraclass correlation coefficient (Snedecor and Cochran, 1967). A second method of establishing the genetic basis of the trait is to examine the proportion of macropterous offspring in relation to the parental morphs. We expect that if the trait has a genetic basis the proportion of macropterous offspring from macropterous parents will be greater than that from micropterous parents. If the trait is polygenic there will nevertheless be a continuous distribution of percentage macroptery in the offspring from a given type of parental cross. Having demonstrated that there is a genetical basis to the trait and that it is polygenic we proceed to estimate the additive component, the heritability.

The general statistical background for the estimation of heritability from family data is outlined in Dempster and Lerner (1950) and Bull et al. (1982). The first step is to compute the intraclass correlation coefficient. Three separate methods are available which I shall call the Anova method (Elston, 1977), the Maximum Likelihood method and the $\chi^{2}$ method. The rationales underlying the latter two are described by Robertson (1951). Using the Anova method the intraclass correlation, $r$, is computed as

$$
r=\frac{\left(\mathrm{MS}_{\mathrm{A}}-\mathrm{MS}_{\mathrm{W}}\right)}{\left(\mathrm{MS}_{\mathrm{A}}+(k-1) \mathrm{MS}_{\mathrm{W}}\right)}
$$

where $\mathrm{MS}_{\mathrm{A}}$ is the mean square among families, $\mathrm{MS}_{\mathrm{W}}$ is the mean square within families and $k$ is equal to $\left(\mathrm{N}-\sum_{\mathrm{i}=1}^{\mathrm{c}=1} n_{\mathrm{i}}^{2} / N\right) /(C-1)$, where $n_{\mathrm{i}}$ is the number of individuals in family $\mathrm{i}, C$ is the number of families and $N$ is the total number of individuals $\left(N=\sum_{\mathrm{i}-1}^{c} n_{\mathrm{i}}\right)$. The $\mathrm{MS}_{\mathrm{A}}$ and $\mathrm{MS}_{\mathrm{W}}$ are estimated by

$$
\begin{aligned}
\mathrm{MS}_{\mathrm{A}} & =\frac{\sum m_{\mathrm{i}}^{2} / n_{\mathrm{i}}-\left(\sum m_{\mathrm{i}}\right)^{2} / N}{(C-1)} \\
\mathrm{MS}_{\mathrm{W}} & =\frac{\sum m_{\mathrm{i}}-\sum m_{\mathrm{i}}^{2} / n_{\mathrm{i}}}{(N-C)}
\end{aligned}
$$

where $m_{\mathrm{i}}$ is the number of macropterous individuals in family $i$ and the summation is taken from $\mathrm{i}=1$ to $\mathrm{i}=C$.

Using the $\chi^{2}$ method $\mathrm{r}$ is computed from the expression.

$$
r=\frac{\left(\chi^{2}-(C-1)\right)}{C}
$$

where $\chi^{2}$ is

$$
\chi^{2}=\frac{\sum m_{\mathrm{i}}^{2} / n_{\mathrm{i}}-\left(\sum m_{i}\right)^{2} / N}{p(1-p)}
$$

and $p$ is the mean proportion of macropterous individuals per family $\left(p=(1 / C) \sum\left(m_{\mathrm{i}} / n_{\mathrm{i}}\right)\right.$, see Bull et al., 1982). 
The Maximum Likelihood method, unlike the previous two assumes a constant family size. However, because of its efficiency Robertson (1951) recommends this method above the $\chi^{2}$ method when the variability in $n$ is large. The approximate maximum likelihood estimate of $r$ is

where

$$
r=\frac{2 p(1-p) \sum K_{\mathrm{i}}}{n_{\mathrm{i}}\left(n_{\mathrm{i}}-1\right)}
$$

$$
\begin{aligned}
K_{\mathrm{i}}= & 0 \cdot 5\left[\frac{m_{\mathrm{i}}\left(m_{\mathrm{i}}-1\right)}{p^{2}}+\frac{\left(n_{\mathrm{i}}-m_{\mathrm{i}}\right)\left(n_{\mathrm{i}}-m_{\mathrm{i}}-1\right)}{(1-p)^{2}}\right. \\
& \left.+\frac{2 m_{\mathrm{i}}\left(n_{\mathrm{i}}-m_{\mathrm{i}}\right)}{p(1-p)}\right]
\end{aligned}
$$

The heritability may then be estimated using the methodology outlined by Bull et al. (1982) or by the formula of Robertson and Lerner (1949),

$$
h^{2}=\frac{2 r p(1-p)}{z^{2}}
$$

where $z$ is the ordinate on the standardised normal curve which corresponds to a probability $p$. The standard error of this estimate is given by

$$
\begin{aligned}
\operatorname{SE}\left(h^{2}\right)= & \frac{2 p(1-p)(1-r)(1+(k-1) r)}{z^{2}} \\
& \times\left[\frac{2(N-1)}{k^{2}(C-1)(N-C)}\right]^{1 / 2}
\end{aligned}
$$

With characters that show a continuous distribution the usual method of estimating heritability is by mid-parent/offspring regression. With a threshold character the problem is that an individual's value is not known. However, if data are available from two generations as in the present study we can use an analogous approach by utilizing the family value of the parent in place of its own, unknown value. The rationale for this approach is as follows. As outlined above (and in detail in Roff $1986 a$ ) we assume that there is some continuously varying factor that determines the development of wings. Let the variance within a family be $\sigma$ and assume that this is constant between families. Consider an individual from family $\mathrm{i}$ with some value $T_{\mathrm{i}}$. If $T_{\mathrm{i}}$ exceeds the threshold value $T^{*}$ the animal will be micropterous. The probability that an individual does not exceed $T^{*}$ and hence is macropterous is given by $\int^{T *} Q\left[\left(x-\mu_{\mathrm{i}}\right) / \sigma\right] d x$ where $Q[(x-$ $\left.\left.\mu_{\mathrm{i}}\right) / \sigma\right]$ is $1 / \sigma \sqrt{2 \Pi} e^{-1 / 2\left[\left(x-\mu_{\mathrm{i}}\right) / \sigma\right]^{2}}$ and $\mu_{\mathrm{i}}$ is the mean value of family $i$. The unit of measurement is arbitrary and hence without loss of generality we may assume $\sigma=1$ and $T^{*}=0$ : hence the proba- bility that an individual is macropterous is given by $\int_{-\infty}^{T^{*}} Q\left(x-\mu_{\mathrm{i}}\right) d x$. Letting $y=x-\mu_{\mathrm{i}}$ the preceding expression becomes $\int_{-\infty}^{\mu_{i}} Q(y) d y$. The value of $\mu_{\mathrm{i}}$ is the ordinate on the standardised normal curve which corresponds to $p_{i}$, the proportion of macropterous individuals in family $i$. This value can be obtained from the tables in Finney (1971) or from the approximation given by Page (1977), $(p>0 \cdot 5)$,

$$
\mu_{\mathrm{i}}=x-7 \cdot 45462 / x
$$

where

$$
x^{3}=\left[y+\left(y^{2}+3 \cdot 313164\right)^{1 / 2}\right] / 0 \cdot 08943
$$

and

$$
y=0.62657 \ln [p /(1-p)] .
$$

Thus what we can estimate is the mean for a family but not an individual's value. Using this value for the parental value and computing the parent offspring regression is equivalent to having a normally distributed measurement error in the independent variable. The slope of the regression in such cases is less than that computed when no measurement error exists (Ricker, 1973; Sokal and Rohlf, 1981). Thus the heritability so estimated will be less than that obtained if the individual parental values were known. The advantage of this method over the first described is that maternal effects can be assessed from the regression of mean offspring value on single parent. Furthermore, it is less sensitive to common environmental effects which can bias analyses based on an analysis of variance of full sibs. This problem is alleviated to a degree by the split family design but the above method is a useful confirmation of the estimate of $h^{2}$.

\section{RESULTS}

If there is a genetic component to macroptery we should expect a high correlation between the proportion macropterous in the two cages. The intraclass correlation coefficients are 0.514 for females and 0.646 for males. To compute confidence limits we transform $r$ to $z$ and compute the variance of $z$ as $1 /(n-1 \cdot 5)$ where $n$ is the total number of pairs, 178 (Snedecor and Cochran, 1967). The $z$ values, corrected for bias, are 0.571 and 0.712 both with standard error of 0.0753 . In neither case do the 95 per cent confidence limits encompass zero and hence we may conclude that there is a significant correlation between cages containing members from the same family. The data from pairs of different cages have, therefore, been combined. 
It is known from a previous study (Roff, 1984) that the percentage macroptery varies between the sexes. But do families that show a high proportion of macroptery in one sex do so for the other sex also? The combined results for the $F_{1}$ and $F_{2}$ generations indicate a very high correlation between the proportion macropterous in the two sexes $(r=$ $0.848, t=16.61 d f=108, P<0.001$, arcsine transformation fig. 2). It is apparent that the percentage of macropterous males is generally less than the percentage of macropterous females.

The next question we address is whether the proportion of macropterous offspring is dependent upon the wing morph of their parents. The results of the $F_{1}$ and $F_{2}$ generations were pooled and divided into three classes, $\mathrm{L} \times \mathrm{L} \quad(\mathrm{L}=$ macropterous, $\mathrm{S}=$ micropterous), $\mathrm{L} \times \mathrm{S}$ and $\mathrm{S} \times \mathrm{S}$. The cumulative frequency distributions of the percentage macropterous offspring from these crosses are as expected on the assumption of parental effect on the offspring morph (fig. 3), $\mathrm{S} \times \mathrm{S}$ crosses producing fewer macropterous offspring than $L \times L$ crosses and $\mathrm{L} \times \mathrm{S}$ lying between these two. A Kolmogorov-Smirnov two-sample test between the $\mathrm{L} \times \mathrm{L}$ and $\mathrm{S} \times \mathrm{S}$ data sets indicates that the differences are statistically significant (for females $n_{1}=38$, $n_{2}=33, D=0.464, P<0.01$ and for males $n_{1}=38$, $\left.n_{2}=33, D=0.498, P<0.01\right)$. The crosses involv- ing parents of different wing morphs can be used to test for maternal influence on offspring wing morph in the following way. If there are maternal influences there should be a higher proportion of macropterous offspring from crosses of $\mathrm{L} \times \mathrm{S}$ in which the female parent is macropterous. There are no significant differences (for female offspring $n_{1}=12, n_{2}=27, D=0.305, P>0.05$ and for male $D=0.23, P>0.05)$.

Having established that the wing morph has a polygenic basis we now proceed to estimate the additive component, its heritability. Two methods are used. These methods are described and formulae given above. The first method requires the computation of the intraclass correlation coefficient. Only data from the $F_{1}$ and $F_{2}$ generations, both using only crosses between families, are used. The estimate of the intraclass correlation coefficient is little affected by the algorithm used (table 1) which is probably due in part to the large data base $(110$ families comprising 8574 individuals). The mean proportion of macropterous males is 0.638 and of females 0.758 . Using the method developed by Bull et al. (1982) the heritability estimates are 0.64 and 0.62 for males and females respectively. The method of Dempster and Lerner (1950) gives estimates and standard errors of $0.62 \pm 0.075$ and $0.68 \pm 0.085$ for males

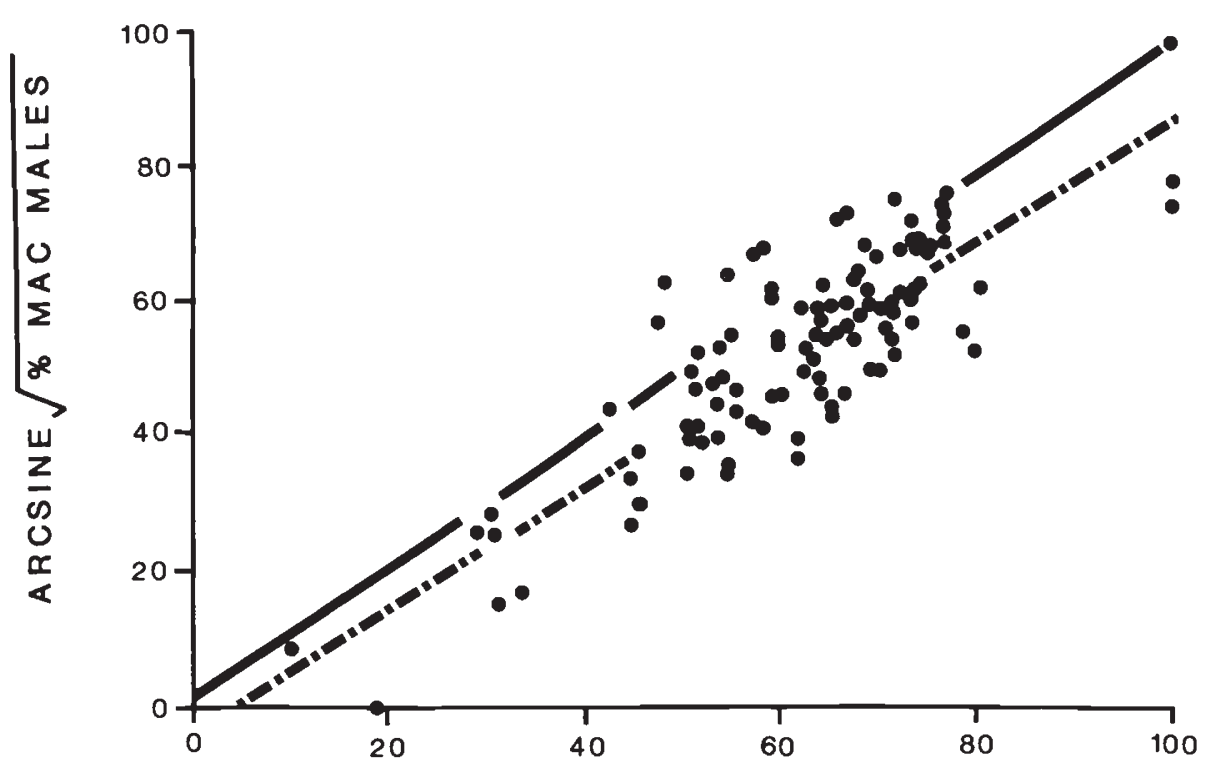

\section{ARCSINE $\sqrt{\% \text { MAC FEMALES }}$}

Figure 2 Percentage macropterous males against the percentage macropterous females from the same family of Gryllus firmus. The solid line is the $1: 1$ ratio and the dashed line the fitted relationship. 


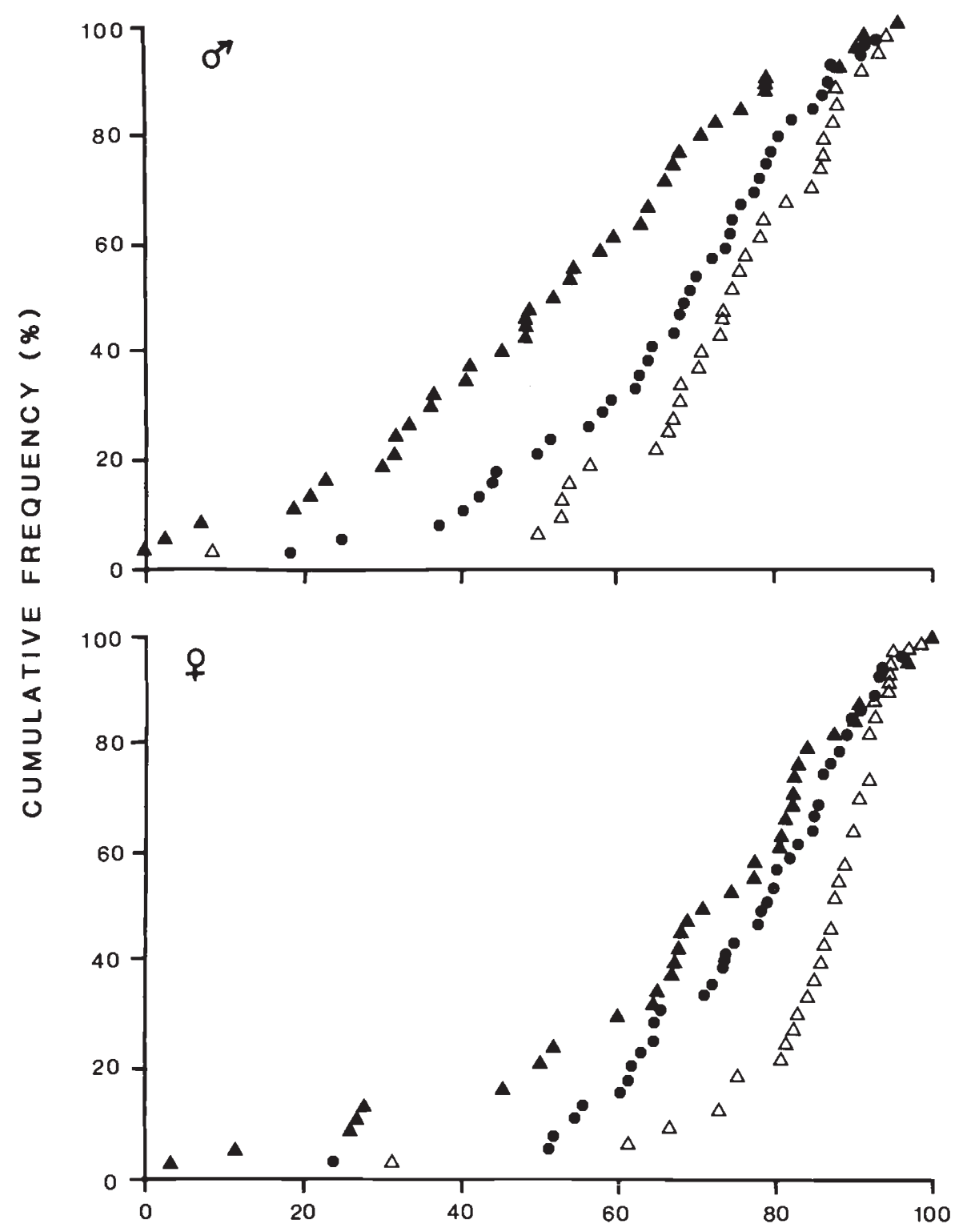

\%MACROPTEROUS PROGENY

Figure 3 Cumulative frequency plots of per cent macropterous males and females from the three types of cross, $S \times S(\triangle), S \times L$ $(\mathbf{O})$ and $\mathrm{L} \times \mathrm{L}(\boldsymbol{\Delta})$. Each symbol denotes the percentage macropterous progeny from a single family.

and females respectively. The two sets of estimates are in close agreement. Furthermore, the differences between males and females is slight and we may reasonably conclude that they estimate a common value. This is, of course, expected from the very high correlation between the percentage macropterous females and percentage macropterous males (fig. 2).

The second method of estimating heritability is an offspring on midparent regression method using the mean of the parent's family as its value. A probit transformation of the data is required which thus excludes two families in which the proportion macropterous is either 0 or 1 . Because the midparent value is measured with error the estimate of heritability will be an underestimate. The heritability estimates using only the data from the $F_{1}$ and $F_{2}$ generations are 0.74 and 0.40 for males and females respectively (table 2 ). The associated standard errors are much larger than 
Table 1 Estimates of the intraclass correlation coefficients for wing dimorphism in $G$. firmus by three different methods. See text for explanation of the methods

\begin{tabular}{lll}
\hline Method & Male & Female \\
\hline ANOVA & $0 \cdot 1917$ & $0 \cdot 1763$ \\
$\chi^{2}$ & $0 \cdot 1976$ & $0 \cdot 1865$ \\
MLE & $0 \cdot 1993$ & $0 \cdot 1843$ \\
\hline
\end{tabular}

with the previous estimates, due in part to the inprecision with which the parental values are estimated and in part to the reduced sample size. The advantage of this method is that the contributions of male and female parent can be assessed separately. The slopes of the regressions are in all four cases about one half of the estimates using the midparent value (table 2), as is to be expected if both parents are contributing equally (Falconer, 1981). This reinforces the conclusion drawn earlier that maternal influences under the experimental conditions are insignificant.

Data on 24 families are available from the $F_{3}$ generation: as these are intra-family crosses they cannot be used to assess maternal and paternal influences. Combining the data from the $F_{1}, F_{2}$ and $F_{3}$ generations does not substantially alter the estimates of heritability (table 2). The analysis based on the formula of Dempster and Lerner (1950) suggests that the heritability in males and females is the same. An improved estimate from the regression method may be obtained by analysing the sexes together using covariance analysis. There is no significant heterogeneity in the slopes $(F(1,166)=2 \cdot 337, P>0.05)$, supporting the previous analysis, and the common slope is 0.55

Table 2 Heritability estimates for wing dimorphism in $G$. firmus derived using family means as estimates of parental and progeny values

\begin{tabular}{|c|c|c|c|c|}
\hline Regression & $r^{\mathrm{a}}$ & $n^{\mathrm{b}}$ & slope $^{c}$ & $\mathrm{SE}$ \\
\hline \multicolumn{5}{|l|}{$F_{1}$ and $F_{2}$} \\
\hline$q$ on midparent & $0 \cdot 32^{*}$ & 60 & 0.40 & $0 \cdot 16$ \\
\hline$\delta$ on midparent & $0.58^{*}$ & 62 & 0.74 & $0 \cdot 14$ \\
\hline$\uparrow$ on $\$$ parent & 0.22 & 60 & $0 \cdot 15$ & 0.09 \\
\hline$q$ on of parent & $0 \cdot 19$ & 60 & 0.21 & $0 \cdot 14$ \\
\hline$\delta$ on $q$ parent & $0.47^{*}$ & 62 & 0.33 & 0.08 \\
\hline$\delta$ on $\delta$ parent & $0 \cdot 26^{*}$ & 62 & $0 \cdot 29$ & $0 \cdot 14$ \\
\hline \multicolumn{5}{|l|}{$F_{1}, F_{2}$ and $F_{3}$} \\
\hline$\delta$ on midparent & $0.56^{*}$ & 86 & 0.68 & 0.11 \\
\hline
\end{tabular}

a: Correlation coefficient

b: Number of families

c: For offspring on midparent $\mathrm{h}^{2}=$ slope, for offspring on a single parent $h^{2}=2 \times$ slope

* Significant at 5 per cent level or greater (fig. 4). This estimate of heritability is not significantly different from those previously derived ( 0.62 and 0.68 ) but is less, as predicted.

The covariance analysis can be extended to examine the combined effect of the estimated midparent value and the actual wing morph of the parent on the wing morph of the offspring. The mean offspring value for each sex was regressed on the estimated midparent value using the wing morphs of the parents as covariants ( 3 covariates, $\mathrm{L} \times \mathrm{L}, \mathrm{L} \times \mathrm{S}, \mathrm{S} \times \mathrm{S})$. In neither sex is there significant heterogeneity in the slopes (for female offspring $F(2,78)=0 \cdot 27$, for males $F(2,80)=0.06$ ) but there is a significant effect due to the type of cross (for females $F(1,80)=13.44, P<0.001$ and for males $F(1,82)=10 \cdot 59, P<0.01)$.

In both males and females there is a significant correlation between the proportion of macropterous offspring produced at $17 \mathrm{~L}: 7 \mathrm{D}$ and that at 12L:12D (for males $r=0 \cdot 79, t=4 \cdot 44, d f=12, P<$ 0.001 and for females $r=0.83, t=5 \cdot 23, P<0.001$ : arcsine transformation in both cases, fig. 5). However, in both cases, particularly in the males, there is a reduction in the proportion macropterous at $12 \mathrm{~L}: 12 \mathrm{D}$. At $17 \mathrm{~L}: 7 \mathrm{D} 4$ families out of 14 produced no macropterous males whereas at $12 \mathrm{~L}: 12 \mathrm{D}$ 12 families produced no macropterous males $\left(\chi^{2}=\right.$ $9 \cdot 3, P<0 \cdot 01)$. At extreme environmental conditions one typically obtains either 0 per cent or 100 per cent macroptery in wing polymorphic species (Harrison, 1980; Roff, 1986a, b). At these extremes, heritability is obviously reduced to zero. We might, therefore, expect to find a general decrease in heritability as these extremes are approached. The shift from 4 families to 12 families producing no macropterous males is suggestive of a reduction in heritability at $12 \mathrm{~L}: 12 \mathrm{D}$. This may be tested in the following manner. Consider those families that produced some macropterous males at 17L:7D but none at 12L:12D. A detectable reduction in heritability will have occurred only if there is significant between-family variation in the proportion of macropterous males produced at 17L:7D. There is no significant heterogeneity between families $\left(\chi^{2}=3 \cdot 91, d f=6, P>0 \cdot 1\right.$, one family excluded from the analysis because its expected value is less than 1).

An alternative method of analysis is to examine the heterogeneity between families at the two photoperiods. Only the female data are suitable for this analysis. At 17L:7D there is significant heterogeneity between families $\left(\chi^{2}=24 \cdot 82, d f=\right.$ 13, $P<0.05)$ and at 12L:12D the same degree of heterogeneity is obtained $\left(\chi^{2}=25 \cdot 44, d f=13\right.$, $P<0.05)$. The above two analyses suggest that 


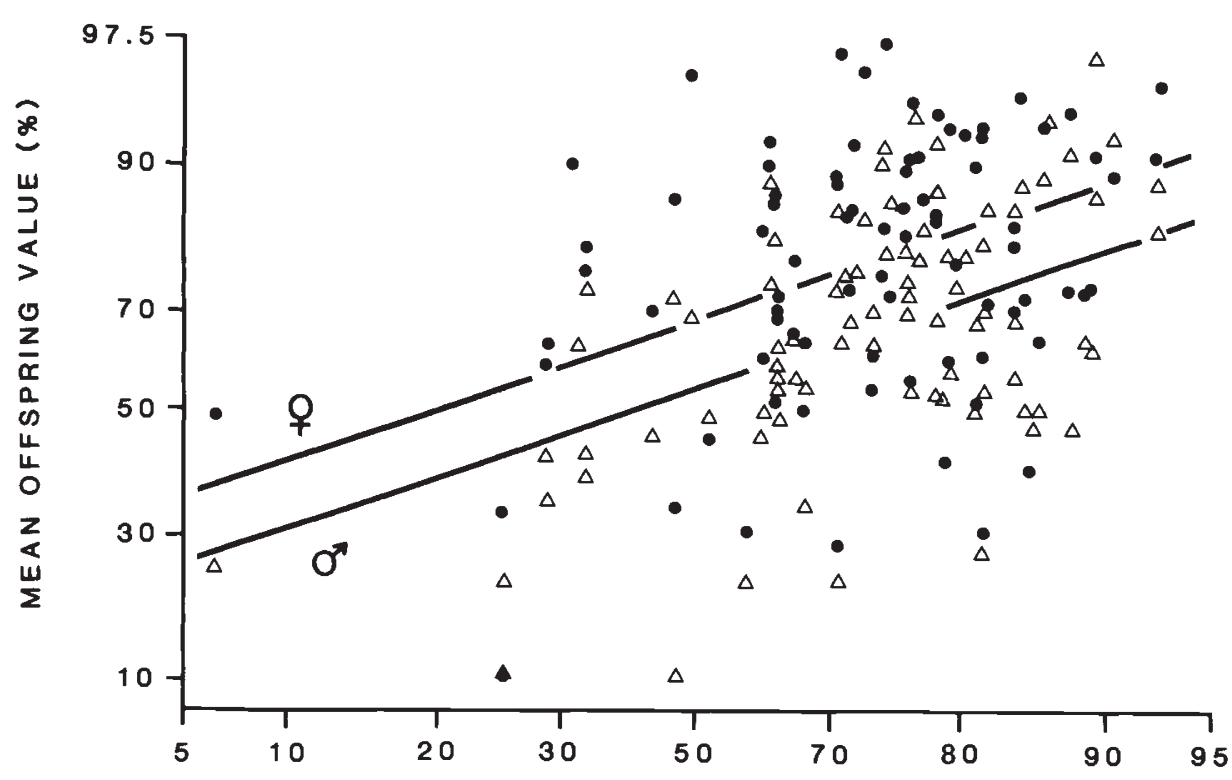

ESTIMATED MIDPARENT VALUE (\%)

Figure 4 The percentage macropterous males $(\Delta)$ and females $(\odot)$ against the mean percentage macropterous females in the families of their parents. Data transformed as described in text. Fitted regression lines are shown.

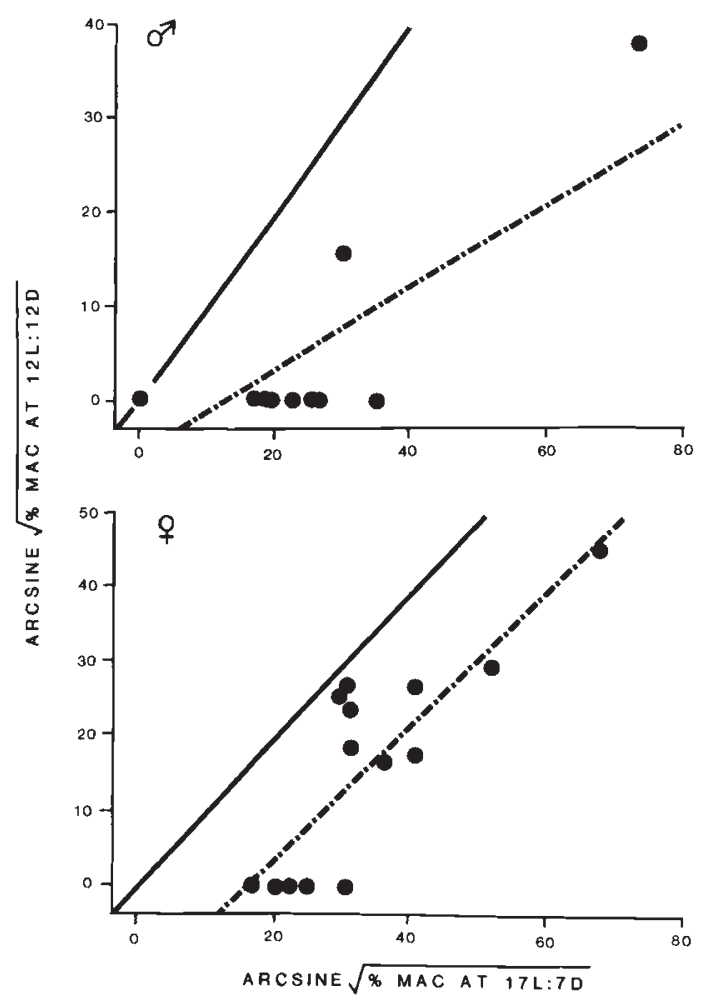

Figure 5 The relationship between the per cent macroptery in a family raised in two different photoperiods. Solid line is line of equality, dashed line the fitted regression line. heritability under the two photoperiods is approximately the same. Sample sizes, however, are small and hence tests for differences insensitive. A more extensive analysis, with larger sample sizes and more environmental combinations is presently underway.

The effect of changes in temperature are more dramatic: the frequency of macropterous males was reduced from 21.2 per cent $(n=137)$ at $30^{\circ} \mathrm{C}$ to 0 per cent $(n=57)$ at $25^{\circ} \mathrm{C}$. Similarly the frequency of macropterous females declined from $57 \cdot 1$ per cent $(n=126)$ at $30^{\circ} \mathrm{C}$ to $15 \cdot 7$ per cent $(n=70)$ at $25^{\circ} \mathrm{C}$. Because these data are based on offspring of unknown parentage no estimate of heritability is possible. However, the data suggest that $\mathrm{h}^{2}$ is reduced at $25^{\circ} \mathrm{C}$ compared to $30^{\circ} \mathrm{C}$.

\section{DISCUSSION}

Whereas wing length in insects with continuous variation, such as $D$. melanogaster, is part of a suite of morphological traits, wing dimorphism is more directly connected with patterns of life cycle adaptation. In a habitat that is very ephemeral, such as sites of rotting fruit or fungi, dispersal is essential for persistence and selection will favour a population of individuals which are fully capable of flight. However, many sites persist for several 
generations and in such circumstances we might predict the evolution of non dispersing individuals. This has been demonstrated theoretically (Van Valen, 1971; Roff, 1975; Järvinen and Vepsäläinen, 1976) and the decline in the proportion of macropterous individuals following colonisation of a newly seeded meadow actually observed over time in the coleopteran species, Apion virens, Sitona hispidula, S. sulcifrons and Phytonomus nigrirostris (Stein, 1977). The genetic basis of wing morph has been established in Sitona hispidula (Jackson, 1928) and Apion virens (Stein, 1973; Roff, 1986a). In both species the trait is determined by a single locus with 2 alleles, brachyptery being dominant. The invasion of new habitats by macropterous individuals of wing polymorphic species of carabids has also been observed (Boer, 1970; Meijer, 1974). Microgeographic variation in the proportion of macropterous individuals that can be correlated with habitat stability has been recorded in leafhoppers (Denno, 1976, 1978, 1979; Denno and Grissell, 1979; Denno et al., 1980; Rey and Strong, 1983) and such variation has been observed between species in Gerris spp. (Vepsäläinen, 1973, 1974a, b, 1978; summarised in Table 11 of Dingle, 1980; Calabrese, 1979). A genetic basis for wing morph determination has been demonstrated in both leafhoppers and Gerridae (data summarised in Roff, 1986a). In these groups inheritance is polygenic with significant genotype-environment interaction.

At any given site there will be a gradual diminution over time of the proportion of macropterous individuals, due to migration of at least some of this morph (Roff 1986b). Such a decrease might be suboptimal in species colonising early successional stages in that the quality of a habitat might be expected to decline over time. As plant succession proceeds an increase in dispersal rate will be favoured. However, different habitats will be at different stages in succession and rates of succession may vary between sites: thus there may be no single optimal dispersal rate and hence selection will tend to preserve genetic variation. A second response to selection for an increased dispersal rate over time is selection for genotypeenvironment interactions. There are considerable laboratory data indicating that crowding and/or nutrition affects the proportion of macroptery in a variety of species (Honek 1976a). The potential selective advantage of such responses is obvious: however, only infrequently are the laboratory results extended to field tests. In the aphids the sedentary mode of life makes it relatively easy to establish the potential importance of crowding and nutritional effects on wing morph (for a review of population dynamics and field densities see Dixon, 1977). It is also probably reasonable to expect crowding to affect wing determination in natural populations of leafhoppers but within the Orthoptera the importance of crowding under natural conditions is far from clear except in some species such as Schistocerca gregaria (Uvarov 1966, 1977). The general response to increased crowding is an increase in the proportion of macropterous individuals. There are obvious selective advantages to such a response provided that the increased density is reflected in increases in the succeeding generation. For multivoltine species such a correlation might be expected but for univoltine species present densities may be poor predictors of densities in the following year and hence the response may have little or no selective advantage.

A second class of genotype-environment interactions are those in which the environmental component is some climatic variable such as temperature or photoperiod. In G. firmus the percentage of macropterous individuals decreases with decreasing photoperiod (fig. 5). Similarly the percentage macroptery declines with temperature. The heritability at the two photoperiods appears to be approximately the same but the dramatic decrease in percentage macroptery at the lower temperature suggests that heritability may be drastically reduced at this temperature. In northern Florida, from whence this stock was derived, photoperiod varies during the year from $10 \mathrm{~L}: 14 \mathrm{D}$ to $14 \mathrm{~L}: 10 \mathrm{D}$ and mean daily temperature from approximately $11^{\circ} \mathrm{C}$ to $28^{\circ} \mathrm{C}$. The air temperature may be misleading because in a closely related species Gryllus pennsylvanicus the growth rate at the air temperature monitored in the field was far less than observed in free ranging crickets (Roff, unpublished data). It seems likely that the dark colour of the crickets raises their body temperature above the ambient when exposed to incident radiation (cf. Begon, 1983). The proportion of macropterous individuals in Northern Florida varies over the year from 0 per cent to approximately 23 per cent (Veazey et al., 1976; both sexes combined), the percentage of macropterous males being consistently less than that of the females, as found in the present laboratory study. The annual percentage of macropterous females in 9.73 per cent and of males $4 \cdot 15$ per cent (data from table 2, Veazey et al., 1976). This low incidence of macroptery suggests that overall, heritability in the field might be quite low. However, the relatively high peak of 23 per cent may result in an increase in heritability in those individuals maturing at this time. In 
Gryllus rubens, coexistent with $G$. firmus, the incidence of macroptery can exceed 50 per cent (Veazey et al., 1976). In the subspecies of G. firmus, G.f. bermudensis field collections indicate a percentage macroptery of "at least 30 per cent" (Kevan, 1980). Thus a high heritability may potentially be realised under natural conditions.

Environment-genotype interactions may be a consequence of the physiological basis of wing morph determination (Roff, 1986 b). The significance of this variation is that, providing it has a genetic component, selection can produce an appropriate rate of dispersal. Responses to habitat deterioration have an obvious selective advantage: responses to photoperiod and temperature may be selected and maintained because they generate the appropriate rate of density-independent dispersal.

The proportion of macropterous males in $G$. firmus is consistently less than that of females. A survey of the literature for other insects indicates that while this is also generally true for other Orthoptera it is not so for other orders. In Homoptera and Hemiptera the ratio appears to show no general trend whereas in the Coleoptera the ratio is generally $1: 1$. The Psocoptera and Hymenoptera are peculiar in that in those species surveyed only one sex is dimorphic, although in neither order is the sex the same between species. Dispersal of males may be advantageous in that there may be reduced competition for mates in new habitats: on the other hand a dispersing male runs the risk of not finding a mate. In some cases individuals may be highly dispersed and hence males must actively search for mates, in which case flight ability will be of obvious advantage. If females do not mate before dispersing and most females are macropterous, males that are unable to follow females to the new habitats may have little reproductive success. Thus the relative advantage of a male being macropterous will depend upon the particularities of the life history and habitat and the lack of any overall trend across orders probably reflects such differences.

Since neither macropterous males nor females need disperse, the occurrence of dimorphism in wing morph suggests that there must be a cost to possessing the ability to disperse. In females this appears to be a lengthened pre-reproductive period and reduced fecundity (Roff, 1986a). It is a reasonable hypothesis that gonad development is delayed in macropterous males, but this has been demonstrated only in Callosobruchus maculatus (Utida, 1972). Alternatively the dimorphism in males may be a consequence of the dimorphism in females and be of no selective advantage. That the propor- tion macropterous differs between the sexes argues against this interpretation although such a difference might be due to hormonal differences associated with sex. More research on the possible costs of being winged in males is clearly needed.

Acknowledgements I should like to thank Ms Catherine Helik for her invaluable aid in the rearing of the crickets and Drs Kurt Sittman and J. A. Endler for comments on the manuscript. This study was supported by a N.S.E.R.C. operating grant A7764.

\section{REFERENCES}

ALEXANDER, R. D. 1968. Life cycle origins, specialization and related phenomena in crickets. Quart. Rev. Biol. 43, 1-41.

ANDREWARTHA, H. G. AND BIRCH, L. C. 1954. The distribution and abundance of animals. Univ. Chicago Press, Chicago. $782 \mathrm{pp}$.

BEGON, M. 1983. Populations and weather: the effects of insolation on Chorthippus brunneus. Ecol. Entomol. 8(4), 361-70.

BOER, P. J. den. 1970. On the significance of dispersal power for populations of carabid-beetles (Coleoptera, Carabidae) Oecologia. 4, 1-28.

BULL, J. J., VOGT, R. C. AND BULMER, M. G. 1982. Heritability of sex ratio in turtles with environmental sex determination. Evolution 36, 333-341.

CAlABRESE, D. M. 1979. Pterygomorphism in 10 Nearctic Species of Gerris. Am. Midl. Nat. 101, 61-68

DEMPSTER, E. R. AND LERNER, I. M. 1950. Heritability of threshold characters. Genetics. 35, 212-236.

DENNO, R. F. 1976. Ecological significance of wing polymorphism in Fulgoroidea which inhabit tidal salt marshes. Ecol. Ent, 1, 257-266.

DENNO, R. F. 1978. The optimum population strategy for planthoppers (Homoptera: Delphacidae) in stable marsh habitats. Can. Ent. 110, 135-142.

DENNO, R. F. 1979. The relation between habitat stability and the migratory tactics of planthoppers (Homoptera: Delphacidae). Misc. Publ. Ent. Soc. Amer. 11, 41-49.

DENNO, R. F. AND GRISSELL, E. E. 1979. The adaptiveness of wing polymorphism in the salt marsh-inhabiting planthopper Prokelisia marginata (Homoptera: Delphacidae). Ecology 60, 221-236.

DENNO, R. F., RAUPP, M. J., TALLAMY, D. W. AND REICHELDERFER, C. F. 1980. Migration in heterogeneous environments: differences in habitat selection between the wing forms of the dimorphic planthopper, Prokelisia marginata (Homoptera: Delphacidae). Ecology 61, 859-867.

DINGLE, H. 1980. Ecology and Evolution of Migration In: Gauthreaux, S. A. Jr. (ed.), Animal Migration, Orientation and Navigation, Acad. Press. 387 pp.

DIXON, A. F. G. 1977. Aphid ecology: life cycles, polymorphism and population regulation. Ann. Rev. Ecol. Syst. 8, 329-353.

ELSTON, R. C. 1977 . Estimating "Heritability" of a Dichotomous trait. Response. Biometrics. 33, 232-233.

FALCONER, D. S. 1981. Introduction to quantitative genetics, 2nd Edn. Longman, New York. 340 pp.

FINNEY, D. J. 1971. Probit analysis, 3rd ed. Camb. Univ. Press, Cambridge, $331 \mathrm{p}$.

HARRISON, R. G. 1979. Speciation in North American field crickets: evidence from electrophoretic comparisons. Evolution, 33, 1009-1023. 
HARRISON, R. G. 1980. Dispersal polymorphisms in insects. Ann. Rev. Ecol. Syst. 11, 95-118.

HARRISON, R. G. AND AR NOLD, J. 1982. A narrow hybrid zone between closely related cricket species. Evolution 36, 535552.

HONEK, A. 1976. Factor influencing the wing polymorphism in Pyrrhocoris apterus (Heteroptera, Pyrrhocoridae). Zool Jb. Syst. Bd. 103, 1-22.

JACKSON, D. J. 1928. The inheritance of long and short wings in the weevil, Sitona hispidula, with a discussion of wing reduction among beetles. Trans. $R$. Soc. Edinburgh. 55, 665-735.

JÄRVINEN, O. AND VEPSÄLÄINEN, K. 1976. Wing dimorphism as an adaptive strategy in water striders (Gerris). Hereditas. $84,61-68$.

KEVAN, D. McE. 1980. The taxonomic status of the Bermuda beach cricket (Orthopteroida: Gryllidae). Syst. Ent. 5, 8395.

MEIJER, J. 1974. A comparative study of the immigration of carabids (Coleptera, Carabidae) into a New Polder. Oecologia 16, 185-208.

PAGE, E. 1977. Approximations to the cumulative normal function and its inverse for use on a pocket calculator. Appl. Statis. 26, 776.

REY, J. R. AND STRONG, R. D. JR. 1983. Immigration and extinction of salt marsh arthropods on islands: an experimental study. Oikos 41, 396-401.

RICKER, W. E. 1973. Linear regression in fishery research. $J$. Fish. Res. Bd. Canada 30, 409-434.

ROBERTSON, A. 1951. The analysis of heterogeneity in the binomial distribution. Ann. Eugenics 16, 1-15.

ROBERTSON, A. AND LERNER, I. M. 1949. The heritability of all-or-none traits: viability in poultry. Genetics 34, 395-411.

ROFF, D. A. 1975. Population stability and the evolution of dispersal in a heterogeneous environment. Oecologia 19, 217-237.

ROFF, D. A. 1984. The cost of being able to fly: a study of wing polymorphism in two species of crickets. Oecologia. 63, 30-37.

ROFF, D. A. 1986a. The evolution of wing dimorphism in insects. Evolution (in press).

ROFF, D. A. $1986 \mathrm{~b}$. The evolution of wing polymorphism and its impact on life cycle adaption in insects. In Taylor, F. and R. Karban (eds.), The Evolution of Insect Life Cycles, Springer-Verlag (in press).
SNEDECOR, G. W. AND COCHRAN, W. G. 1967. Statistical Methods, 6th. ed. Iowa State Univ. Press, Ames, Iowa. 593 pp.

SOKAL, R. R. AND ROHLF, F. J. 1981. Biometry (2nd ed.), W. H. Freeman and Company, 859 pp.

Southwood, T. R. E. 1962. Migration-an evolutionary necessity for denizens of temporary habitats. Proc. Int. Congr. Ent. XIth (1960). 3, 54-58.

STEIN, W. 1973. Zur Vererbung des Flugeldimorphismus bei Apion virens Herbst (Col., Curculinoidae). $Z$ ang. Ent. 74, 62-63.

STEIN, W. 1977. Die Beziehung zwischen Biotop-Alter und Auftreten der Kurzflugeligkeit bei Populationen dimorpher Rüsselkäfer-Arten (Col., Curculionidae), Zeitschrift angew. Ent. 83(1), 37-39.

UTIDA, S. 1972. Density dependent polymorphism in the adult of Callosobruchus maculatus (Coleoptera: Brunchidae). J. stored Prod. Res. 8, 111-126.

UVAROV, B. 1966. Grasshoppers and Locusts, Vol. 1, Camb. Univ. Press, Lond. and N.Y.

Uvarov, B. 1977. Grasshoppers and Locusts, Vol. 2, Camb. Univ, Press, Lond. and N.Y.

VAN VALEN, L. 1971. Group selection and the evolution of dispersal. Evolution 25, 591-598.

VEAZEY, J. N., KAY, C. A. R., WALKER, T. J. AND WHITCOMB, W. H. 1976. Seasonal abundance, sex ratio and macroptery of field crickets in northern Florida. Ann. Ent. Soc. Amer. $69,374-380$.

VEPSÄLÄINEN, K. 1973. The distribution and habitats of Gerris Fabr. species (Heteroptera: Gerridae) in Finland. Ann. Zool. Fennici 10, 419-444.

VEPSÄLÄINEN, K. 1974a. The life cycles and wing lengths of Finnish Gerris Fabr. species (Heteroptera: Gerridae). Acta Zool. Fennica 141, 1-73.

VEPSÄLÄINEN, K. 1974b. Determination of wing length and diapause in water striders (Gerris Fabr., Heteroptera). Heriditas 77, 163-175.

VEPSÄLÄINEN, K. 1978. Wing dimorphism and diapause in Gerris: determination and adaptive significance. In $\mathbf{H}$. Dingle (ed.), Evolution of insect migration and diapause, Berlin-Heidelberg-New York: Springer Verlag.

WALKER, T. J. 1980. Mixed oviposition in individual females of Gryllus firmus: graded proportions of fast-developing and diapause eggs. Oecologia 47, 291-298. 